\title{
The Current Certification Model: Does It Reflect Nursing Knowledge?
}

Gloria Joachim, RN, MSN

Associate Professor, University of British Columbia School of Nursing

Vancouver, BC

Marcy Saxe-Braithwaite, RN, MScN, MBA

Vice President, Programs and Chief Nursing Officer

Providence Continuing Care Centre

Kingston, ON

Heather Mass, RN, MSc

Chief of Nursing, Children's and Women's Health Centre of British Columbia

Vancouver, BC

Robert Calnan, RN, MEd

President, Canadian Nurses Association

Manager, Burns, Plastics, EENT and Urology, Capital Health Region

Victoria, BC

Bernadet Ratsoy, RN, MSc

Associate Dean of Health Sciences, British Columbia Institute of Technology (Retired) Burnaby, BC

\section{Abstract}

Although certification is widely believed to be important, little recognition is given to certified nurses. Many nurses choose not to certify or recertify based largely on the lack of recognition and the perception that the certification process is costly and lengthy. The aim of this project was to collect data, in a two-dimensional format, about the amount of time used to prepare for the Canadian Nurses Association (CNA) certification exams. On one axis, the specialties were noted, and on the other, the educational background was noted. A secondary aim of the project was to explore whether the concept of opportunity cost loss is useful for assessing the value of certification. Data from a group of certifying nurses were collected. Preparation time varied widely between individuals 
and specialties. The variation in preparation time suggests that differences may be due to age and education. Recommendations are given to change the structure of the certification process from a single-tiered exam to a multi-tiered exam that would reflect differences in nursing education.

The purpose of certification is (1) to establish standards in specialty practice that will promote excellence in nursing care for Canadians, (2) to confirm competence in specialty practice and (3) to identify nurses who meet the national standards with a credential (CNA 2004a). Cary (2001) notes that certification should protect the public from unsafe care, distinguish between levels of care provided and give certified nurses a competitive advantage in the workplace. Many institutions now require specialty education or certification for employment in specialty areas (personal communication, Human Resources, St. Paul's Hospital, Vancouver General Hospital, April 2002).

\section{History of Certification in Canada}

Certification in Canada has a short history. The certification program of the Canadian Nurses Association (CNA) began in 1980 with the recommendation by an ad hoc committee that CNA develop a certification program in the specialties (CNA 2004a). The criteria for a specialty group to qualify for credentialling status included having established standards; addressing a recurrent practice phenomenon; having a role description for practitioners; being supported by literature, education and research; having identified the number and distribution of nurses in the specialty; and having sufficient numbers of practitioners to support certification (CNA 2002: 5). At the time that data were collected for this study, CNA certification was available in 11 specialties; in 2004, 14 specialties were listed (CNA 2004a). Certification status spans five years. Recertification is available in all specialties.

\section{Prerequisites for Certification}

The eligibility criteria for becoming a certified nurse in Canada for all specialties other than Occupational Health consists of two options (CNA 2002: 2). In the first, the nurse must hold current Canadian registration, have accumulated 3,900 practising hours in the specialty during the last five years and have a supervisor or consultant in the specialty verification. In the second, one must hold current Canadian registration, have a nursing degree or post-basic nursing specialty course with at least 300 hours of work in the specialty, accumulate a minimum of 1,950 practice hours in the specialty during the last three years and have a supervisor or consultant verify the experience.

To be eligible for certification in the specialty of Occupational Health, there are also two options. In the first, one must hold current Canadian registration, have accu- 
mulated at least 5,000 hours of work in Occupational Health during the last five years, have accumulated 75 hours of continuous education in Occupational Health during the last five years and have supervisor or consultant verification of activities. In the second, one must hold current registration, have a nursing degree or Occupational Health specialty course that is at least 300 hours long, have accumulated 75 hours of continuing education in Occupational Health during the last five years and have supervisor or consultant verification of activities.

\section{Methods}

The CNA certification office assisted by mailing a questionnaire to nurses who wrote the 2001 certification exams. Participants were asked about demographics, educational background and specialty, and were asked to record, on a weekly basis, the amount of time invested in all aspects of preparation for the certification exam. Data would be plotted in a two-dimensional database with specialty on the $\mathrm{x}$ axis and educational background on the y axis. If differences between the specialties occurred, the data could become the basis for generating equivalencies between specialties. For example, it may be determined that specialty $\mathrm{A}$ is more difficult than specialty $B$, specialty $B$ is more difficult than specialty $C$ and specialty $B=$ specialty D. Using this logic, equivalencies and rankings could be established among the specialties. If differences within the specialties occurred, they would be analyzed depending upon the educational background.

\section{Results}

Forty nurses certifying in nine specialties returned the completed questionnaire. While this is a small sample, definitive trends emerged. All were women with a mean age of 43. Thirteen had diplomas in nursing, 22 had baccalaureate degrees and five had master's degrees. Nineteen had some formal specialty education in the specialty in which they were certifying, and 21 had no formal specialty education. Nurses certified in the following specialties: Critical Care, Emergency, Gerontology, Nephrology, Occupational Health, Oncology, Perioperative and Psychiatric/Mental Health.

Nurses in the specialties of Critical Care and Emergency had the most specialty education and were the youngest nurses with specialty education. In the Gerontology group, none of the nine nurses had specialty education.

There was a wide variety in the mean amounts of preparation time for each specialty. The Perioperative specialty (mean of 40 hours) had the shortest amount of time, while Oncology (mean of 136.6 hours) had the longest. For individuals, preparation time varied from 20 to 350 hours. The youngest nurses with specialty education used the least amount of preparation time, while the oldest and most experienced nurses used the longest amounts of preparation time. 


\section{Discussion}

The objective of this study was to construct a two-dimensional database that had the specialties certified by CNA on the $y$ axis and the differential educational preparation on the $\mathrm{x}$ axis. This design facilitates capturing data along the $\mathrm{y}$ axis that describes the differences between specialties, and data along the $\mathrm{x}$ axis that describes the differences within specialties depending upon educational background.

Since limited funds were available for this work, CNA was approached and asked for help in distributing the questionnaire. CNA agreed to assist, and attached the questionnaire along with a mailout to all those who applied for the certification exam. Therefore, the data were not collected according to true survey methodology with a stamped return envelope and follow-up (Dillman 1978) and can only serve as indicators.

Forty questionnaires were returned from approximately 2,000 that were mailed. The rate of return (2\%) may be due to the inability to follow true survey methodology (Dillman 1978). The number of nurses who wrote the certification exam and the number that passed is unknown. The sample of 40 represents people who were willing to record their preparation time on an ongoing weekly basis from the point at which they began to prepare for certification until the exam. The willingness of the 40 respondents to record their preparation time, week after week, shows a high degree of motivation; therefore, the number of hours recorded are likely to be accurate.

Since responses were not obtained from all 11 specialties, it is hard to make a case for calculating differentials and equivalencies among specialties. Responses were received from nine specialties, and each specialty had between three and seven respondents.

With regard to the $\mathrm{x}$ axis (or each specialty), preparation time was recorded depending upon the educational background of each respondent. Several trends emerged. A longstanding assumption is that certification represents the highest level of knowledge within a given specialty, and passing a certification exam is a yardstick by which all examinees of a given specialty are measured. Furthermore, if it is assumed that all those writing a certification exam have the same knowledge base before the exam, one would expect that preparation time leading to passing the exam would appear as a cluster of numbers without wide variation.

No literature was found to indicate that prior education affected the amount of preparation time needed for the certification exams. One might expect that those nurses with considerable experience would need less preparation time owing to their existing body of knowledge. However, the indicators showed the opposite. This finding raises two questions: (1) Is length of experience a relative factor that 
predetermines the amount of preparation time requisite to prepare for the exam? and (2) Is age or youth, which was associated with a shorter preparation time, an indicator of the ability to write an exam?

As Cary (2001) notes, certification denotes excellence. Being certified creates a differential between those who have the certification credential and those who do not. Differentials are a widely accepted way to recognize those who successfully complete education programs (e.g., BSN, MSN, NP, PhD). The level of recognition varies according to the level of preparation and achievement. Currently, the profession struggles to find a place for certification within the recognized educational processes. Cary (2001) reports that only $29 \%$ of nurses surveyed received rewards or recognition for becoming certified.

Buerhaus (1998) notes that the number of hours worked and the decision to work or not to work are positively correlated with wages. A possible secondary outcome that might be calculated from the database is the opportunity cost (OC) loss in obtaining certification. OC is a concept commonly used in commerce and economics to assign value to educational processes. The American Medical Association has used this method to assess the value of specialty education of physicians (Hsiao et al. 1992). OC loss is the measure of forgone alternatives (Frank et al. 2003). In other words, it is the potential loss of salary that the person would have earned had she or he worked instead of studied. Assigning costs to the educational process is an important notion because time, a scarce commodity, can be converted and assessed in real terms, and can be assigned a real monetary value.

It is easy to apply this concept to the study of a four-year baccalaureate, a one- or two-year master's degree, a specialty program or a doctoral program. These are lengthy processes that assign large losses to individuals who complete each process. The logical conclusion in using $\mathrm{OC}$ as a measure of educational processes is the longer the educational process, the greater the OC loss incurred by the individual. One may argue that a person who obtains a master's or doctoral degree has an OC in the hundreds of thousands of dollars and should be rewarded accordingly. The question arises: Can the concept of OC loss be applied to the amount of preparation time required for the certification process?

In this study, data regarding hours used were collected, and wage rates are public knowledge. Therefore, calculating OC loss for those who returned the questionnaire became a possibility. In other words, it would be possible to demonstrate each nurse's real investment in time and money to write a certification exam. Furthermore, it would be possible to assess whether preparation time for passing a certification exam is as lengthy, difficult and costly as many nurses claim. 
Based on the data collected, the OC loss calculation would be meaningless, since the wide variation in preparation time within the specialties creates a numerical paradox. The longer the amounts of preparation time, the higher the calculated OC loss for a particular nurse. That translates into a higher investment in time to write the exam. Simultaneously, the shorter the preparation time, the less calculated OC loss accrues to that person and a smaller investment in time. It would be inaccurate to say that a nurse who needed more preparation time, and invested more time, is valued more.

Based on the wide variety of preparation time within the specialties that appeared to be related to age and educational background, a logical question arises: Should certification remain a single-tiered, uniform process, or should it be a multi-tiered process depending upon educational background? In other words, should certification reflect tested knowledge based upon the highest level of educational preparation? For example, is it expected that a clinical nurse specialist (CNS) will have more knowledge than a diploma-prepared nurse? If the answer is yes, then a multitiered certification process should be developed. If the answer is no, that raises questions about the value of higher education for nurses.

\section{Establishing the Relationship between Certification and Nursing Knowledge}

Currently, certification entails a single-tiered examination that does not reflect educational differences among those who certify. This study shows a relationship between education, age and preparation time. Length of experience did not appear to contribute positively to the amount of preparation time needed. Formal educational processes with a credential such as BSN or MSN contain new educational content. Although review materials are provided, the certification exam has a limited amount of new knowledge required, and the prerequisites to write the exam rely largely on experience (CNA 2004b). Therefore, in its current form, the certification exam is largely based on past knowledge and experience.

In order to elevate the status of certification from an exam based largely on prior knowledge to a process representing continuous education and new knowledge, a multi-level model of certification and recertification is proposed. The goal is to create equivalencies so that certification is a true indicator of excellence in nursing specialties. Table 1 shows four levels, where three levels represent certification and the fourth recertification. Level 1 , for diploma nurses, includes theoretical content to bridge the gap between diploma-prepared nurses and baccalaureate-prepared nurses. Level 2 is for diploma nurses who have passed Level 1 and baccalaureateprepared nurses without formal specialty education. Level 2 includes specialty content. Level 3 contains new content and trends and is for diploma-prepared nurses who have passed Levels 1 and 2, diploma nurses who completed Level 1 and have specialty education or baccalaureate-prepared nurses with specialty education. 
Level 4, recertification, involves a structured demonstration of updated knowledge in the specialty over the last five years. Knowledge of new developments and current research would be important. All new content could be delivered using modules, weekly assignments and an evaluation process.

Table 1.

A multi-level certification model

\begin{tabular}{lll} 
Level & Goal & Result \\
\hline Level 1 & $\begin{array}{l}\text { Theoretical content for diploma-prepared } \\
\text { nurses }\end{array}$ & BSN theoretical knowledge \\
Level 2 & $\begin{array}{l}\text { Specialty education content for diploma- } \\
\text { prepared nurses who passed Level 1 or } \\
\text { BSN nurses without specialty education }\end{array}$ & $\begin{array}{l}\text { Equivalence of formal } \\
\text { specialty education }\end{array}$ \\
& $\begin{array}{l}\text { Content for diploma-prepared nurses who } \\
\text { passed Levels 1 and 2 or Level 1 with } \\
\text { specialty education, or for BSN graduates } \\
\text { who completed specialty education }\end{array}$ & $\begin{array}{l}\text { New knowledge in the specialty } \\
\text { including current research and } \\
\text { trends }\end{array}$ \\
& $\begin{array}{l}\text { Recertification; for those nurses with Level 3 } \\
\text { Level 4 }\end{array}$ & $\begin{array}{l}\text { New knowledge in the last 5 } \\
\text { years, including research and } \\
\text { current trends }\end{array}$
\end{tabular}

Restructuring the certification process changes the focus from passing an exam based on prior knowledge and experience to a credential based on standardized, state-of-the-art specialty knowledge. Recertification becomes a high-level update. These changes would enhance the value of certification for the profession and for the public. Currently, Revenue Canada does not recognize certification as continuous education. Converting the certification process from experienced-based knowledge to continuous learning would make certification eligible for a tax deduction and demonstrate the value added to the profession.

Further examination of certification is essential for the future of the nursing profession. Studies examining a multi-tiered process would enhance the credibility of certification and may encourage more nurses to recognize its value and certify in their specialty areas.

Correspondence may be addressed to Gloria Joachim, University of British Columbia School of Nursing, T-201 Wesbrook Mall, Vancouver, BC V6T 2B5; phone 604-822-7463; email: joachim@nursing.ubc.ca. 


\section{References}

Buerhaus, P.I. 1999. "Is a Nursing Shortage on the Way?” Nursing Management 30(2): 54-55.

Canadian Nurses Association. 2002.

"Certification Program." Retrieved April 8, 2003. $<$ http://www.cna-nurses.ca/pages/certification/ certification_frame.html $>$.

Canadian Nurses Association. 2004a. "The Origins of Nursing Specialty Certification in Canada." Retrieved February 9, 2005.

$<$ http://www.cna-nurses.ca/CNA/nursing/certification/about/history/default_e.aspx>.

Canadian Nurses Association. 2004b. "Frequently Asked Questions." Retrieved February 9, 2005.

$<$ http://www.cna-nurses.ca/CNA/nursing/certification/apply/faq/default_e.aspx $>$.
Cary, A. 2001. "Certified Registered Nurses: Results of the Study of the Certified Workforce." American Journal of Nursing 101(1): 44-52.

Dillman, D.Z. 1978. Mail and Telephone Surveys: The Total Design Method. New York: Wiley-Interscience.

Frank, R.H., B.S. Bernanke, L. Osberg, M.L. Cross and B.K. MacLean. 2003. Principles of Microeconomics. Toronto: McGraw Hill Ryerson.

Hsiao, W.P., D.I. Braun, E.R. Dunn, D. Becker, D.K. Yntema, E. Verrilli, S. Stamenovic and S. Chen. 1992. "An Overview of the Development and Refinement of the Resource-based Relative Value Scale. Medical Care 30(11/Suppl.): NS1-NS12. 